\title{
The Dynamics of Individual Differences in Teaching/Learning of English as a Second/Foreign Language
}

\author{
Sultan H. Alharbi
}

Department of English Language \& Translation, College of Languages \& Translation

King Saud University, Riyadh, Saudi Arabia

E-mail: suhalharbi@ksu.edu.sa

Received: September 15, 2021 Accepted: October 22, 2021 Published: December 11, 2021

doi:10.5296/ijl.v13i6.19316

URL: https://doi.org/10.5296/ijl.v13i6.19316

\begin{abstract}
The subject of individual learner differences (IDs) in English as a Second/Foreign (ESL/EFL) Language teaching and learning is an area which has been much debated and investigated. Since these differences vary according to the geographical or cultural influences of the learners, variations in results and opinions among language instructors are inevitable. However, the indubitable fact is that these differences considerably influence the ESL/EFL language learners' performances. Individuals are different in personality styles, and these personality styles are influenced by age, cultural background and a whole lot of other factors. These IDs lead to dynamism in language acquisition. The current study thus examined three set of IDs to determine how they affect the learning style preferred by individuals. The individual differences analyzed in this study include: race, exposure to English Language, and personality type (i.e., introvert or extrovert). The study concluded that while race and exposure to English Language affected the preferred learning style significantly as expected English language acquisition, personality style, however, did not have an influence on the preferred learning style for this study sample. IDs are extremely complex, with a large number of variables. As a result, it is critical for researchers as well as English language instructors to identify the source of the problem from a psychological standpoint and consider variables that would aid in Second Language Acquisition (SLA) improvement.
\end{abstract}

Keywords: Individual differences, Introvert-extrovert, Language acquisition, Learning style, Personality traits, Second language acquisition 


\section{Introduction}

A common tenet in the field of SLA is that research in the field has focused on the learners' behavior (Miao, 2015). The belief of a particular learner plays a peculiar approach in their learning and achievements (Bernat \& Gvozdenko, 2005). Hence, to understand a learner, we must first understand his identity which includes their belief about learning. This identity of learners also entails their demographics, their ideas, opinions, values and expectations (Norton \& Costa, 2017). All these have to do with the learners' psychology. Learning has continually been studied in the realm of psychology. Beliefs are considered to be dynamic rather than stable (Csizér, et al., 2010). When it involves language, beliefs could be assumptions about the function and nature of language, or it could be a multidimensional one. It is important to understand in-depth the beliefs that guide learners' action. The relationship between belief and the cognitive learning process has also been explored by various studies in the field (e.g., Sinatra, 2001). These beliefs and these cognitive behaviors change by academic domains, and this is one of the reasons language learning is considered to be dynamic, rather than being a mental representation of a fixed a-priori consult. This dynamism is consistent with the development of a person's character (Lapsley \& Power, 2006), which is thoroughly explained in many educational psychology research (Sinatra, 2001; Lapsley \& Power, 2006). More importantly, the belief about SLA and its development have also been studied longitudinally (Ortega \& Iberri-Shea, 2005).

Culture and the social environment have a major influence on belief of individuals (Karahanna, Evaristo et al. 2005; Cronk, 2016). Educational research has found major influences on the formation of beliefs as students' make headway in using writing strategies (e.g., Fazilatfar, et al., 2014). This encompasses how confident the students become of their own abilities, and the development of multidimensional mental notes. The development of these multidimensional mental notes were in turn found to affect strategy development as used by ESL/EFL learners (Fazilatfar, et al. 2014). Overall, it is pertinent to understand what the dynamism of IDs means for learners in specific learning contexts.

Educational psychology serves an important purpose in measuring the dynamism of IDs in learners. The discussion of educational psychology leads to research on acquisition in contact circumstances and in the situations where learners believe what their own personal social identities are. Humans are both similar and unique in many characteristics (Schumpe \& Erb, 2015). Our characteristics vary with quite a lot of parameters (Schumpe \& Erb, 2015). IDs are visible, but some of these differences can, however, only be inferred through research and systematic observation of behaviors (Haslam, et al. 2006). In language learning, the question arises as to why some learners acquire the language so naturally, and yet others struggle and stumble through second language learning.

There are significant differences in the results of Second language (L2) learning tests and evaluations. The basis of this disparity is not singularly definable but is multilayered and complex and is a result of not only IDs in intellectual capabilities, but also from variances in emotional factors like personality and motivation (Levine, et al. 2020). While scrutinizing these factors and others separately can enlighten on the quality of L2 acquisition, much more 
can be discovered by looking into how various aspects and influences act together to facilitate learning procedures and results. The current study aims to contribute to the general understanding of the basics and traces of differences in the acquisition of ESL/EFL by concentrating on three main issues that have been presented to impact it - IDs in cognitive abilities, exposure conditions, and linguistic complexity - and the interactions between them (Marengo, 2021).

\subsection{Individual Differences (IDs)}

IDs studies have continually tried to explain the internal characteristics of individuals and give meaning to the observed differences (Haslam, et al. 2006). Internal characteristics definitely play a role in language learning. However, it is also explained by other variables. We are all different, our pasts are different from our presents as well as our futures. Hence, the question arises - "Is it Nature versus Nurture?" Is it only a matter of internal characteristics or our experiences? It is not either of the above. Rather, it is a collection of variables working together (Purba 2018). Various studies have been undertaken to find out and ascertain the reasons for these internal or external IDs in the context of the teaching and learning of English as a second/foreign language. Many characteristics individual traits have been assumed to act as vital factors which are held responsible for this kind of diversity in language acquisition. These traits have been largely the general physical factors such as age, gender, and various personality attributes, and some of them are more specific, like the workings of our brains which directly affects our learning of a second/foreign language (Levin, et al., 2020).

Our brains, like our fingerprints, are one-of-a-kind. This variation is caused by both genetic and phenotypic factors. Throughout one's life, one's brain changes and adapts, and This means that skills and behavior can change as well (Ortega \& Iberri-Shea, 2005). SLA researchers are well aware that equal exposure to a foreign language does not result in equal levels of competence in L2 learners. As a result, researchers are interested in these causes of variation in order to promote the development of second/foreign language skills, which is also the purpose of the current study. Personal factors are termed 'learner-internal' (Ramli, et al. 2018). These are intrinsic abilities that are common to each person. The other factors are termed 'learner-external' (Ramli, et al. 2018). The idea that particular behaviors are more favorable for language learning is an interesting ground for research. In the ideal sense, one who learns the language admirably would possess the following factors - he or she would be a good communicator, have excellent memory, is studious, creative and courageous; additionally, he is a willing risk-taker (Buarqoub, 2019). Undoubtedly, not all learners are like this. Learners vary in their personal characteristics.

\subsection{Learner-Internal Factors: Ability}

Ability refers to both intelligence and language aptitude (Teepen, 2004). Expectedly, learners with a higher level of ability will be more successful language learners (Teepen, 2004). Differences in the physical and chemical structure of the brain, according to neurobiologists, generate variance in talents and aptitudes (Osterhout, et al. 2008). Higher levels of achievement in language classes could be attributed to cognitive or social variables 
(Osterhout, et al. 2008). Most of the time, it is a mix of the two and this translates to higher scores being connected to a greater degree of intelligence for some, and a rich literacy environment being responsible for the role of successful language learning for others. Memory and analytic abilities are significant in SLA, but only when they are combined with creative and practical ability to form what is called successful intelligence (Vijayalakshmi \& Patchainayagi 2020). Success is determined by the alignment of instructional conditions with the pattern of talents. In other words, ESL/EFL students do better in language learning settings when they are taught in a style that matches how they think.

\subsection{Personality Traits}

\subsubsection{Extraversion-Introversion}

Extraversion-Introversion is a phenomenon that occurs as a result of biological and social factors. It is important as a research section in studying IDs since it is an important personality trait (Kayaoğlu, 2013). Extroverts exhibit behaviors that are more prone to sensory stimulation (Kayaoğlu 2013). On the other hand, introverts try to avoid situations that are overly stimulating (Zelenski, et al. 2014). It has been proven that extroverts outperform introverts in short-term memory (STM) and working memory (WM) (Özbay, et al. 2017). These distinctions are chemical in nature. The results vary depending on how personality traits were measured (self-report vs. other ratings), the language being learned, the learners' nationality, and which language variables were measured and how. Researchers concluded that extraversion is better suited for language learning since SLA is one that requires mingling and actual communication (Özbay, et al. 2017). However, extraversion skills do not necessarily translate to better test scores. It however usually mean better oral fluency for such ESL/EFL learners (Dewaele \& Furnham, 1999). On the other hand, introverts tend to use less colloquial language than extroverts (Dewaele \& Furnham, 1999). Introverts typically struggle with Foreign Language Acquisition (FLA) and are less willing to communicate (Ortega \& Iberri-Shea, 2005) (Kayaoğlu, 2013). Vocabulary learning strategies strongly correlated with extraversion (Marin, 2005). Still, a subset of introverts tend to outperform extroverts in language learning. This is so because a subset of introverts usually show higher intelligence in certain situations (Saklofske \& Kostura, 1990). Introverts perform best when studying in a familiar environment (Dewaele \& Furnham 1999).

As a result, the present study aims to examine three set of IDs to determine how they affect the learning style preferred by individuals. The IDs analyzed in this study include: race, exposure to English Language, and personality type (i.e., introvert or extrovert). The remainder of this article is divided into the following parts. The method adopted for the present study are presented in Section (2). While Section (3) provides the main findings and their discussion, section (4) provides concluding remarks based on the findings obtained, describing the implications of the findings, limitations of the study, and recommending some suggestions for future research.

\section{Method}

Data for this study was collected using a well-structured questionnaire designed as an online 
survey. The questionnaire was designed as an online form in order to make it accessible for participants. The questionnaire is divided into three parts. The first part of the questionnaire related to the demographic of respondents, including race/ethnicity, the country of residence, the country where respondents had their secondary education, and how long respondents have been studying English Language. Some of these responses translated to the individual differences noticed among learners. The second part of the questionnaire collected information about the personality traits of respondents (i.e., introversion or extraversion), their attitude in 'pressure situations' and their sense of adventure. The third part of the questionnaire collected information on the predominant learning style adopted by learners (i.e., visual, auditory, group or individual).

As for the introversion-extraversion scale, the methods of determination include the Eysenck Personality Inventory (EPI) has been profitably used in a lot of personality determination studies (e.g., Bodling \& Martin, 2011). Comprehensively, the scale determines four quadrants of personality study, i.e., Introversion-Extraversion, and Neuroticism-Stability. Similar to the current study, other studies have simplified this scale further to include or determine the introversion-extraversion attitudes of individuals (e.g., Tiwari, et al. 2009). Items were selected from this scale and applied to the participants of this study. Bülbül \& Arslan (2017) detailed items that account for individual differences, including tolerance to pressurizing situations and the spirit of outgoingness or adventure displayed by individuals. Regarding learning styles, the Perpetual Learning Style Preference Questionnaire (PLSPQ) was used as a reference (Rhouma 2016). Further, Reid (1987) developed a scale which divides learning styles into: auditory, kinesthetic, visual, group and individual. The items on this scale were used to determine the predominant learning styles of the participants of this study (Rhouma 2016): visual, auditory, group or individual.

A total number of 60 participants took part in the present study. The demographic data of the participants were analyzed with the use of descriptive statistics (i.e., frequencies and percentages). The independent variables of IDs chosen include: Race, number of years respondents have been learning English Language, and Introversion or Extraversion personality of respondents. The predominant learning style of respondents were also determined, and these was considered to be the dependent variables. Respondents were tested for the following learning styles: visual, auditory, group and individual. The data were gathered and analyzed using the statistical package SPSS (V. 23).

\section{Results and Discussion}

In total, there were 60 respondents for this study. The discussions of their responses and the results deduced from them are presented in this section.

\subsection{Race, Number of Years Respondents Have Been Learning English Language, and Introversion or Extraversion Personality of Respondents}

The study respondents were from different nationalities across different races including Blacks - 16 (27\%), Asians -16 (27\%) and Arabs - 28 (47\%). The diversity of students is expected as students were selected solely for the purpose that they were ESL/EFL learners. 
However, no person of the White race (Caucasian) filled the form as they are considered to be pure native English speakers. As for the country of origin, the respondents of the study, gathered through an online form, originated from Nigeria, Ghana, India, Japan, Malaysia, Indonesia, Saudi Arabia, Yemen, Qatar and Sudan. Furthermore, the majority of the students held their pre-university education in these varying countries. The data presented by the respondents meant that all of these respondents were individually different based on their demographics. This difference meant that they have varying types of exposure to English language depending on their race, country of origin, and the number of years they have been studying English Language. This differences also meant that there were IDs observed among the respondents.

Regarding how long they have been learning English language, 8 (13\%) of the respondents revealed that they have been learning English language for 0 - 7 years; 28 (47\%) said they have been learning English Language for the past 8 - 15 years; the remaining 24 (40\%) said they have been learning English Language for more than 15 years. These statistics point to an additional IDs among the respondents. Measuring Introversion-Extraversion personalities of respondents employing the Eysenck Personality Inventory (EPI), the students responded to the following questions shown in Table 1. Respondents answering 'Yes' to these questions meant that they are identified as being extroverts, excepts for questions 4 and 5 (i.e., Do you tend to keep in the background on social occasions? Are you mostly quiet with other people?). The rearrangement of the pattern of these two questions meant that the researcher created some ambiguity in order not to stick to a pattern that would have been perceived by the respondents. Answering ' $N o$ ' to these two questions meant that the respondents are identified as being extroverts. Calculating averages, results gathered for the response 'Yes' amounted to 216; responses corresponding to ' $N o$ ' amounted to 144, including responses for ' $Y e s$ ' and ' $N o$ ' that have been switched appropriately as in the case of questions 4 and 5 .

Table 1. Participants' responses for measuring the introversion-extraversion scale

\begin{tabular}{lcc}
\hline \multirow{2}{*}{ Questions } & \multicolumn{2}{c}{ Answers } \\
\hline Q1: Are you a talkative person? & Yes & No \\
Q2: Are you rather lively? & 52 & 44 \\
Q3: Can you easily get some life into a dull party? & 40 & 8 \\
Q4: Do you tend to keep in the background on social occasions? & 28 & 32 \\
Q5: Are you mostly quiet with other people? & 36 & 24 \\
Q6: Do other people think of you as being lively? & 44 & 16 \\
Total & $\mathbf{2 1 6}$ & $\mathbf{1 4 4}$ \\
\hline
\end{tabular}

Dividing these totals (i.e., 216 and 144, respectively) by the number of questions (i.e., 6 questions) means that $60 \%$ of the respondents identified as being extroverts, and $40 \%$ as being introverts. The impact of introversion and extraversion on language learning has been studied in many contexts. Students differ in how they pick up language (Mischel \& Shoda, 1995). The complexity is attributed to cognitive, affective, personality and other factors (Jacobs, 2014). Extraversion is believed to have a positive impact on language learning 
because of a high level of interaction with other individuals (Flanagan \& Addy, 2019). On tolerance to pressure, $40(67 \%)$, of the respondents believed that that can easily maneuver themselves when it came to dealing with undesirable situations. They considered themselves to be positive and optimistic in finding a solution to undesirable events they did not formerly envisage. 20 (33\%) of these respondents, however, noted that they find themselves constantly ruminating over situations that are beyond their control. They find themselves continually looking for the cause of what resulted in a failure in a situation in the past. As for their attitude when faced with a situation that requires them to be adventurous, 16 (27\%) of the respondents revealed that they liked moments of adventure. This points to an extraversion nature. The remaining $44(73 \%)$ revealed however that they prefer to live in peaceful situations, with only occasional moments of challenges. This points to an introversion nature.

\subsection{Predominant Learning Styles}

Observing the predominant learning styles and their advantages using the Perpetual Learning Style Preference Questionnaire (PLSPQ), the statements in each of the items were positively-worded. The ordering of the items was performed by regrouping together each of the four components. Then each item was labeled under its subcomponent. The sum was computed according to the subcomponents. The items in the scale were represented by the following eight statements as can be seen in Table 2. The adjoining numbers are the frequency of the respondents identified with each of the statements.

Table 2. Frequency of the respondents identified with each of the statements in PLSPQ

\begin{tabular}{clc}
\hline$\#$ & Items & Frequency \\
\hline 1 & I learn better by reading what the teacher writes on the chalkboard. & 20 \\
2 & I understand better when I read instructions. & 48 \\
3 & When the teacher tells me the instruction, I understand better. & 32 \\
4 & I remember things I have heard in class better than things I have read. & 28 \\
5 & I learn more when I study with a group. & 12 \\
6 & I enjoy working on assignments with two or three classmates. & 36 \\
7 & When I study alone, I remember things better. & 52 \\
8 & I prefer working on projects by myself. & 28 \\
\hline
\end{tabular}

The first two sentences (No. $1 \& 2$ ) represented items which the respondents selected to show that they identified as visual learners (i.e., 68). Sentences $3 \& 4$ represented items which the respondents selected to show that they identified as auditory learners (i.e., 60). Sentences $5 \&$ 6 represented items which the respondents selected to show that they identified as group learners (i.e., 48). Sentences $7 \& 8$ represented items which the respondents selected to show that they identified as individual learners (i.e., 80). The numbers in front of these sentences represent the frequency of the respondents who identified with each of the questions. The mean for each of these categories of learners: visual, auditory, group and individual was calculated by dividing the total frequency in each category by 2 because each of the category contained 2 sentences each. Table 3 below displays the means and total percentage for each of these learning styles. 
Table 3. Means and total percentage for each of four learning styles

\begin{tabular}{lcc}
\hline Learning style & Mean & Percentage \\
\hline Visual & 34 & 57 \\
Auditory & 30 & 50 \\
Group & 24 & 40 \\
Individual & 40 & 67 \\
\hline
\end{tabular}

As can be seen in Table 3, the predominant learning style for the respondents in this study is the individual learning style. This means that an individual's preferred method of absorbing, processing, and comprehending information is referred to as their learning style. Extroverts are more likely than introverts to prefer a group learning style over an individual learning style (e.g., Jacobs, 2014; Kayaoğlu, 2013). This is understandable because extroverts thrive in groups. In the current study, however, despite the fact that the majority of the participants identified as extroverts, the most common learning style was determined to be individual. This, on the other hand, is not entirely out of place. Similar findings were also observed in other studies (e.g., Flanagan \& Addy 2019).

Table 4. Chi-Square Table for Observed vs. Expected variables of Perpetual Learning Style Preferences (visual, auditory, group, individual)

\begin{tabular}{lcccc}
\hline & Visual & Auditory & Group & Individual \\
\hline Observed (O) & 34 & 30 & 24 & 40 \\
Expected (E) & 15 & 15 & 15 & 15 \\
\hline
\end{tabular}

Results of chi-square test for Observed vs. Expected variables of Perpetual Learning Style Preferences (visual, auditory, group, individual) (Table 4) indicate indicates that the learning styles are distinct and independent of another $(p=0.0)$. Language learning styles and tactics appear to be one of the most important factors affecting second language achievement. English language instructors must be aware of the most common learning styles, and thus they can assist their students by creating instruction that caters to the demands of students with various style preferences and teach students how to enhance their learning processes (Gilakjani, 2011). Furthermore, because learning styles are critical aspects in learners' learning, identifying learners' learning styles aids educational planners and language instructures in providing learners with the required educational assistance and resources. Individuals develop learning styles and approaches based on their particular peculiarities, just as they do with other skills, that is, via practice (Gilakjani, 2011).

\subsection{The Influence of Race, Exposure to English Language, and Personality Style on the Preferred Learning Style}

The results indicate statistically significant differences $(p=.03)$ for Race (Arab, Black, and Asian) in Perpetual Learning Style Preference (visual, auditory, group, individual). This finding suggests that the environment in which a person grows and develops has a significant impact on their ability to learn. English language instructors must be sensitive to the cultural values, practices, language, learning preferences, involvement, and familial patterns of 
different ethnic groups. Further, English language instructors face a difficult task in accommodating ethnic variety in their English language teaching settings, which influences learning patterns (Trofimovich \& Turuševa, 2015).

Additionally, differential analysis for exposure to English Language against Perpetual Learning Style Preference shows statistically significant differences $(p=.05)$. This means that the number of years spent learning English and the amount of exposure to the language have an impact on students' preferred learning styles and, as a result, on how and how effectively they learn the language. Individuals may feel as if they have been struggling to grasp the English language for years with little progress. Learners who begin learning a language in their early years learn the language more quickly than adults ( $\mathrm{Hu}, 2016)$. Language acquisition is influenced by one's age, and the quality of output improves when language is taught at a young age. When a person reaches adulthood, they would have perfected their language. This is why many parents are ensuring that their children begin learning the language at a young age. The brain is inclined to language acquisition success at a certain point in human development. Children, on the other hand, have a number of challenges in language learning, including a lack of attention, an inability to notice regularities and informal relationships, a lack of problem-solving skills, and a lack of experience. Adults, on the other hand, may readily overcome these issues ( $\mathrm{Hu}, 2016)$.

On the other hand, the results indicate that the introversion-extroversion attitude has no influence on language learning for this group of students $(p=.06)$. The majority of learning programs are designed with the extroverted personality in mind. Students are awarded for participating in language class, for example. That is an activity that the extrovert finds appealing. Extroverts are more likely to ask questions, volunteer to read, and lead study groups than introverts. Extroverts flourish in social situations. They take part in class discussions, give speeches, and present their findings (Flanagan \& Addy, 2019). They learn quickly and actively in this manner. All of these are not only beneficial but also essential (Hu ,2016). Introverts, on the other hand, prefer to conduct their research on their own. They would rather think about what they have learned that day. They prefer to operate more autonomously in the majority of circumstances. These individuals have a place in the world. In the past, students were largely expected to pay attention and work independently (Saklofske \& Kostura, 1990). The key for the teacher is to be able to strike a balance between the two. This is to ensure that both introverts and extroverts can thrive to their full potential. Language instructors can provide choices for solo-reflection work for introverts by considering their characteristics (Jacobs, 2014).

\section{Concluding Remarks}

The current study aimed to add to the mounting body of studies examining the influence of IDs on the ESL/EFL language learners' performances by investigating three set of IDs to determine how they impact the learning style preferred by individuals. The IDs explored in this study included race, exposure to English language, and personality type (i.e., introvert or extrovert). The findings indicated that while race and exposure to English language had an influence on the preferred learning style, personality style, on other hand, did not have a 
significant effect on the preferred learning style for this study sample. Although the findings of the current study may be important to the field of the field of SLA in general and ESL/ESL teaching and learning in particular, it has some limitations, which might be a possible avenue for future studies. One obvious limitation of the study is that the results of this study are based on a broad-based survey. Therefore, further studies utilizing different research methods in this field are needed to ascertain the dynamics of IDs in second language acquisition at a more credible conclusion. Another limitation is that the current study has only examined three set of IDs: race, exposure of English language and personality type: therefore, additional studies are also needed to investigate other factors affecting learning style preferred by ESL/EFL learners. IDs are extremely complex, with a large number of variables. As a result, it is critical for researchers to identify the source of the problem from a psychological standpoint and consider variables that would aid in SLA improvement (Griffiths, 2021). In order to assist ESL/EFL learners in becoming more effective learners, researchers must first understand their learning preferences and attitudes toward language learning. Moreover, it is practical and useful to employ the results obtained in the current study to encourage and facilitate second language learning in a complex, dynamic, and socio-culturally varied language learning atmosphere and to facilitate them to use their best towards successful language learning.

\section{Acknowledgments}

The author expresses his appreciation to the Deanship of Scientific Research at King Saud University, Saudi Arabia, and the Research Centre at the College of Languages \& Translation for offering support for the current article.

\section{References}

Bernat, E., \& Gvozdenko, I. (2005). Beliefs about language learning: Current knowledge, pedagogical implications, and new research directions. Tesl-ej, 9(1).

Bodling, A. M., \& Martin, T. (2011). Eysenck personality inventory. In J. S. Kreutzer, J. DeLuca, \& B. Caplan (Eds.), Encyclopedia of clinical neuropsychology (pp. 1007-1008). New York: Springer.

Buarqoub, I. A. S. (2019). Language barriers to effective communication. Utopía y Praxis Latinoamericana, 24, 64-77.

Bülbül, A. E., \& Arslan, C. (2017). Investigation of patience tendency levels in terms of self-determination, self-compassion and personality features. Universal Journal of Educational Research, 5, 1632-1645.

Cronk, L. (2016). Culture's influence on behavior: Steps toward a theory. Evolutionary Behavioral Sciences, 11, 36.

Csizér, K., Kormos, J., \& Sarkadi, A. (2010). The dynamics of language learning attitudes and motivation: Lessons from an interview study of dyslexic language learners. The Modern Language Journal, 94, 470-487. 


\section{$\triangle$ Macrothink}

International Journal of Linguistics

ISSN 1948-5425

2021, Vol. 13, No. 6

Dewaele, J. M., \& Furnham, A. (1999). Extraversion: The unloved variable in applied linguistic research. Language Learning, 49, 509-544.

Dornyei, Z., \& Skehan, P. (2003). Individual differences in second language learning. In J. Catherine, \& H. Michael (Eds.), The handbook of second language acquisition (pp. 589-630). New Jersey: Blackwell Publishing Limited.

Fazilatfar, A. M., Damavandi, R. R., Sani, R. H., \& Heirati, J. K. (2014). Learners' belief changes about language learning. International Journal of English Language Education, 3, $1-19$.

Flanagan, K., \& Addy, H. (2019). Introverts are not disadvantaged in group-based active learning classrooms. Journal of College Biology Teaching, 45, 33-41.

Gilakjani, A. P. (2011). Visual, auditory, kinaesthetic learning styles and their impacts on English language teaching. Journal of Studies in Education, 2, 104-113.

Griffiths, C., \& Soruç, A. (2021). Individual differences in language learning and teaching: A complex/dynamic/socio-ecological/holistic view. English Teaching \& Learning, 1-15.

Haslam, N., Bain, P., Douge, L., Lee, M., \& Bastian, B. (2006). More human than you: Attributing humanness to self and others. Journal of Personality and Social Psychology, 89, 937.

$\mathrm{Hu}, \mathrm{R}$. (2016). The age factor in second language learning. Theory and Practice in Language Studies, 6, 2164-2168.

Jacobs, G. (2014). Introverts can succeed with cooperative learning. Parole, 4, 83-94.

Karahanna, E., Evaristo, J. R., \& Srite, M. (2005). Levels of culture and individual behavior: An investigative perspective. Journal of Global Information Management, 13, 1-20.

Kayaoğlu, M. N. (2013). Impact of extroversion and introversion on language-learning behaviors. Social Behavior and Personality, 41, 819-825.

Lapsley, D., \& Power, F. C. (2006). Character psychology and character education. Journal of Military Ethics 5, 77-78.

Levine, S. M., Alahäivälä, A. L., Wechsler, T. F., Wackerle, A., Rupprecht, R., \& Schwarzbach, J. V. (2020). Linking personality traits to individual differences in affective spaces. Frontiers in psychology, 11, 448.

Marengo, D., Davis, K. L., Gradwohl, G. Ö., \& Montag, C. (2021). A meta-analysis on individual differences in primary emotional systems and big five personality traits. Scientific Reports, 11, 1-12.

Marin, A. (2005). Extraversion and the use of vocabulary learning strategies among university EFL students in Mexico (Unpublished doctoral thesis). University of Essex, UK.

Miao, R. (2015). Second language learning. In D. W. James (Ed.), International encyclopedia of the social \& behavioral sciences (pp. 360-367). Oxford: Elsevier. 


\section{Al Macrothink}

International Journal of Linguistics

ISSN 1948-5425

2021, Vol. 13, No. 6

Mischel, W., \& Shoda, Y. (1995). A cognitive-affective system theory of personality: Reconceptualizing situations, dispositions, dynamics, and invariance in personality structure. Psychological Review, 102, 246.

Norton, B., \& De Costa, P. I. (2017). Research tasks on identity in language learning and teaching. Language Teaching, 51, 90-112.

Ortega, L., \& Iberri-Shea, G. (2005). Longitudinal research in second language acquisition: Recent trends and future directions. Annual Review of Applied Linguistics, 25, 26-45.

Osterhout, L., Poliakov, A., Inoue, K., McLaughlin, J., Valentine, G., Pitkanen, I. ... Hirschensohn, J. (2008). Second-language learning and changes in the brain. Journal of Neurolinguistics, 21, 509-521.

Özbay, A. Ş., Aydemir, T., \& Atasoy, Y. (2017). Extroversion-introversion in the context of foreign language learning. The International Journal of Educational Researchers, 8, 1-21.

Purba, N. (2018). The role of psycholinguistics in language learning and teaching. Teaching of English Language and Literature Journal, 6, 47-54.

Ramli, N., Muljono, P., \& Afendi, F. M. (2018). External factors, internal factors and self-directed learning readiness. Journal of Education and e-Learning Research, 5, 37-42.

Reid, J. M. (1987). The learning style preferences of ESL students. TESOL Quarterly, 21, 87-111.

Rhouma, W. B. (2016). Perceptual learning styles preferences and academic achievement. International Journal of Arts \& Sciences, 9, 479-492.

Saklofske, D., \& Kostura, D. (1990). Extraversion-introversion and intelligence. Personality and Individual Differences, 11, 547-551.

Schumpe, B. M., \& Erb, H. P. (2015). Humans and uniqueness. Science Progress, 98, 1-11.

Sinatra, G. M. (2001). Introduction: Knowledge, beliefs, and learning. Educational Psychology Review, 13, 321-323.

Teepen, J. (2004). On the relationship between aptitude and intelligence in second language acquisition. Studies in Applied Linguistics and TESOL, 4, 1-9

Tiwari, T., Singh, A. L., \& Singh, I. L. (2009). The short-form revised Eysenck personality questionnaire. Industrial Psychiatry Journal, 18, 27.

Trofimovich, P., \& Turuševa, L. (2015). Ethnic identity and second language learning. Annual Review of Applied Linguistics, 35, 234-252.

Vijayalakshmi, V., \& Patchainayagi, S. (2020). Role of memory in language learning-a review. International Journal of Early Childhood Special Education, 12, 68-76.

Zelenski, J. M., Sobocko, K., \& Whelan, D. C. (2014). Introversion, solitude, and subjective well-being. In R. J. Coplan, \& J. C. Bowker (Eds.), The handbook of solitude: Psychological 
perspectives on social isolation, social withdrawal, and being alone (pp. 184-201). New Jersey, Wiley-Blackwell.

\section{Copyrights}

Copyright for this article is retained by the author(s), with first publication rights granted to the journal.

This is an open-access article distributed under the terms and conditions of the Creative Commons Attribution license (http://creativecommons.org/licenses/by/4.0/) 